\title{
Positron Annilation Lifetime and Glass Transition Temperatures in $\mathrm{CO}_{2}$ Sorption Polystyrene
}

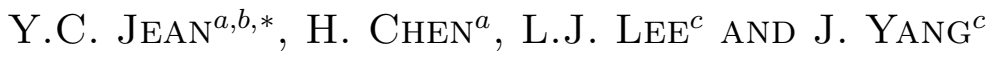 \\ ${ }^{a}$ Department of Chemistry, University of Missouri-Kansas City \\ Kansas City, MO 64110, USA \\ ${ }^{b}$ Center of Membrane Technology, Chung-Yuan Christian University \\ Chung-Li, Taiwan \\ ${ }^{c}$ Department of Chemical and Biomolecular Engineering, Ohio State University \\ Columbus, OH 43210, USA

\begin{abstract}
Positron annihilation lifetime spectroscopy was used to measure the freevolume size and distributions as a function of temperature in polystyrene with and without $400 \mathrm{psi} \mathrm{CO}_{2}$ sorption. The transition temperatures in the polystyrene with $\mathrm{CO}_{2}$ sorption obtained from ortho-positronium lifetimes were found to depend on the thermal cycles and a meta-stable state showing a negative thermal expansion coefficient was observed between $53^{\circ} \mathrm{C}$ and $82^{\circ} \mathrm{C}$ during the first heating up experiment. The observed $T_{\mathrm{g}}$ in polystyrene with, and without $\mathrm{CO}_{2}$ sorption after annealing from ortho-positronium lifetimes were found to be $86^{\circ} \mathrm{C}$ and $91^{\circ} \mathrm{C}$, which are $5^{\circ} \mathrm{C}$ higher, and $10^{\circ} \mathrm{C}$ lower than from the differential scanning calorimetry data, respectively. The observed free-volume variations are discussed in terms of hole expansion, creation, free-volume relaxation, plasticization, and hole filling in amorphous polymers.
\end{abstract}

PACS numbers: 78.70.Bj, 78.66.Qn, 71.60.+z

\section{Introduction}

Basic understanding of the nanoscopic properties of amorphous polymers at the glassy state for $\mathrm{CO}_{2}$ exposure has drawn increasing interest in recent years because of its important industrial applications, such as foam forming, gas separation, synthesis and extraction by supercritical fluids, and the global environmental issues [1]. When $\mathrm{CO}_{2}$ is exposed to a polymer, typically it dissolves into the matrix of polymers by interacting with polymers and subsequently it increases the

*corresponding author; e-mail: jeany@umkc.edu 
chain mobility of the polymer, the so-called plasticizing effect [2]. Apparent effects to polymeric performance are an increase in specific volume and a decrease in glass transition temperature $\left(T_{\mathrm{g}}\right)[3,4]$. While macroscopic thermal and mechanical methods, such as differential scanning calorimetry (DSC), thermogravimetric (TGA), and volumetry, provide viscoelastic properties for plastic industry for the effect of $\mathrm{CO}_{2}$ sorption, nano-scopic approach to investigate the free volume properties could provide fruitful information at the atomic and molecular levels and at the very origin of chain dynamic motion $[5,6]$. While most of knowledge on the free volume dimension and motion has been predicted by theoretical calculation [7], a direct measurement of free-volume size and distribution at the dimension in sub-nanometer and relaxation time on the order of nanoseconds has becoming possible in recent years by using positron annihilation spectroscopy [8]. Positron annihilation lifetime (PAL) spectroscopy is capable of determining size, distribution, and relative fraction of free volume in polymers [9]. This is based on the phenomenon that the positronium (Ps, the bound atom of positron and electron) is found to preferentially localize in the sub-nanoscale free volume $[8,9]$. One of successful applications is to determine the glass transition temperature $\left(T_{\mathrm{g}}\right)$ from the variation of ortho-positronium (o-Ps, the triplet state of Ps) lifetime, which has a direct correlation with the free-volume hole size [10-12].

PAL has been employed to study the $\mathrm{CO}_{2}$ interaction with a few selected polymers, polyethylene (PE) [13], polystyrene (PS) [13], polysulfone (PSF) [14], and polycarbonate (PC) [15]. While PS have been extensively studied using PAL in recent years [16-32], for $\mathrm{CO}_{2}$ exposure, only up to 50 psi has been reported [13]. In this paper, we report the result of free-volume size and distribution and determine the variation of glass transition temperature $\left(T_{\mathrm{g}}\right)$ in polystyrene with and without $\mathrm{CO}_{2}$ sorption under 400 psi pressure at different thermal cycles and compare with the DSC data.

\section{Experiments}

PS resins were from the commercially used products in industry known as AtoFina CX 5197 (melt index: 4.5, MW $=224 \mathrm{~K}$, and dispersion $M_{\mathrm{w}} / M_{\mathrm{n}}=2.4$, $T_{\mathrm{g}}=101.2^{\circ} \mathrm{C}$, DuPont). Ultrahigh purity $\mathrm{CO}_{2}$ gases $(99.99 \%)$ were (supplied from Praxair ) used to expose PS samples in a special designed cell. Two pieces of PS (1 mm thick, $1 \mathrm{~cm} \times 1 \mathrm{~cm})$ were sandwiched in between a positron source (15 $\mu \mathrm{uCi}$ of ${ }^{22} \mathrm{NaCl}$ purchased from DuPont Life Science Division, Delaware), which was sealed in $12 \mu \mathrm{m}$ kapton film. Two identical assembled samples were used to perform PAL experiments as a function of temperature, one for the un-exposed and the other for the exposed experiments. The un-exposed PS sample was used as assembled and the exposed sample was evacuated and annealed at $150^{\circ} \mathrm{C}$ and then cooled to room temperature (r.t.) in a $\mathrm{CO}_{2}$ cell, which was manipulated in a vacuum- sealed stainless steel gas line and the $\mathrm{CO}_{2}$ pressure was regulated at 400 psi and monitored by an Omega transducer pressure gauge (Model 302-1KGY) 
during PAL experiments. The experimental setup and cell design were described in our previous papers $[14,15]$.

The thermal properties (heat flow rate $\mathrm{W} / \mathrm{g}$ ) of PS (sample mass $=c a .10$ $\mathrm{mg}$ ) at ambient atmosphere and at a regulated 400 psi pressures of $\mathrm{CO}_{2}$ were performed using a differential scanning calorimeter (DSC, TA 2920) at a rate of $10^{\circ} \mathrm{C} / \mathrm{min}$ in three cycles (increasing, decreasing, and then increasing). The onset points of DSC trace were taken as the $T_{\mathrm{g}}$, the glass transition temperature of the PS [33].

The positron annihilation lifetime spectra were recorded using a fast-fast coincident PAL spectrometer (resolution 280 ps) at the University of MissouriKansas City [8]. The acquired PAL spectra (2 million counts) were analyzed into three lifetimes using PATFIT program and also into lifetime distributions using MELT program, respectively. The longest lifetime from these analysis $\left(\tau_{3}=2-\right.$ $3 \mathrm{~ns}$ ) is due to the pick-off annihilation of $o$-Ps in free volumes. The mean freevolume radius was calculated from the established semi-empirical equation based on the spherical infinite potential-well model [10-12].

\section{Results and discussions}

We performed the PAL as a function of temperature from r.t. to $150^{\circ} \mathrm{C}$, for un-exposed and $400 \mathrm{psi} \mathrm{CO}_{2}$ exposed PS samples, respectively. Both un-exposed and $\mathrm{CO}_{2}$ sorption PS samples were first used to perform PAL experiments for $48 \mathrm{~h}$ when the PAL data $\left(\tau_{3}\right.$ and $\left.I_{3}\right)$ reached constant values before PAL experiments as a function of temperature began. In order to detect the hysteresis due to thermal cycles, the PAL experiments were performed in three runs: first run in heating up from r.t. to $150^{\circ} \mathrm{C}$, second run in cooling from above $T_{\mathrm{g}}$ to r.t., and third run in heating from r.t. to above $T_{\mathrm{g}}$. Figures 1 and 2 show the results of $o$-Ps lifetimes and intensities as a function of temperature for un-exposed, and $\mathrm{CO}_{2}$ sorption PS, respectively.

\subsection{Un-exposed polystyrene}

In the PAL data in the un-exposed PS as shown in Fig. 1, we have the following observations: (1) o-Ps lifetime increases as a function of temperature, and there is a transition of slope as the temperature further increases, and (2) the $o$-Ps lifetime vs temperature data (left on Fig. 1) in three runs: heating, cooling, and heating, follow the same trend within statistical errors. However, $I_{3}$ data for the first run is very different from the second and the third runs.

The first observation of $o$-Ps increase as a function of temperature is due to the expansion of free volume size (radius) as shown in the right $y$-axis. The transition of $o$-Ps lifetime from the glassy to the rubbery state is easily seen from a low to a high-temperature region. We fitted all $o$-Ps data into two slopes as lines shown in Fig. 1 (left). The intercept temperature is identified as the apparent glass transition temperature $\left(T_{\mathrm{g}}\right)$. The observed $T_{\mathrm{g}}=91.2 \pm+2.4^{\circ} \mathrm{C}$ is significantly lower than the $T_{\mathrm{g}}$ observed by $\operatorname{DSC}\left(=101.2^{\circ} \mathrm{C}\right)$. We also examined the $o$-Ps lifetime 

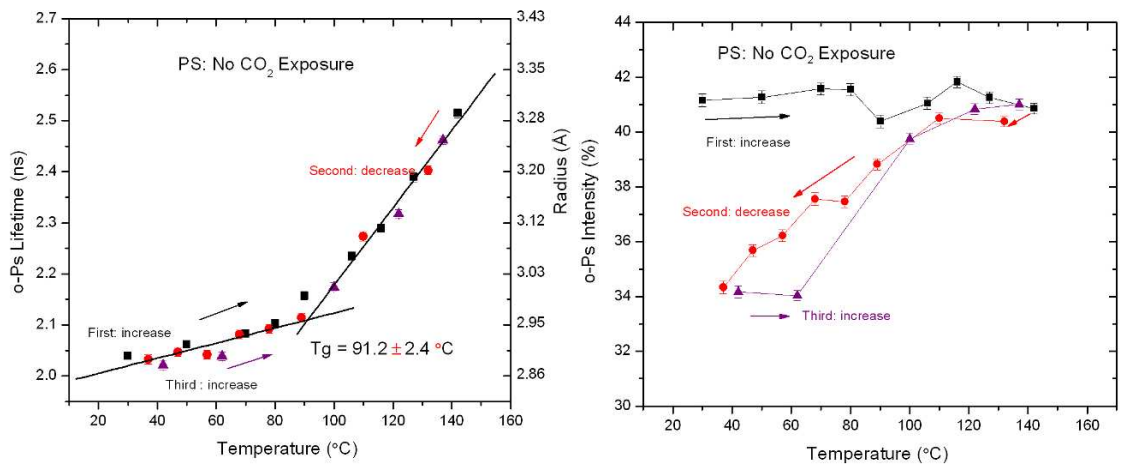

Fig. 1. Ortho-Ps lifetimes and intensities vs temperature in un-exposed PS sample in air. Lines were linear fitting data and the intercept is defined as $T_{\mathrm{g}}$. Three runs from low to high, high to low, and then up again are as indicated.

TABLE I

Glass transition temperatures $\left(T_{\mathrm{g}}\right)$ of PS and $\mathrm{CO}_{2} / \mathrm{PS}$ obtained by different fittings and methods.

\begin{tabular}{c|c|c|c}
\hline \hline PS samples and data & $T_{\mathrm{g}}\left[{ }^{\circ} \mathrm{C}\right] \mathrm{no} \mathrm{CO}_{2}$ & $T_{\mathrm{g}}\left[{ }^{\circ} \mathrm{C}\right]$ under $400 \mathrm{psi} \mathrm{CO}_{2}$ & $\Delta T_{\mathrm{g}}\left[{ }^{\circ} \mathrm{C}\right]$ \\
\hline$o$-Ps lifetime first run: heating & $90.9 \pm 2.5$ & $\begin{array}{c}T^{\prime}=53.1 \pm 1.5 \text { and } \\
T_{\mathrm{g}}=82.2 \pm 2.5\end{array}$ & $\begin{array}{c}37.8 \\
\text { and } 7.9 \\
\text { Av. }=22.9\end{array}$ \\
\hline DSC first run only & & 73.07 & 28.8 \\
metastable $T_{\mathrm{g}}=67.6 \pm 2.0$ & 6.0 \\
o-Ps lifetime second run: cooling & $93.0 \pm 2.1$ & $87.0 \pm 2.0$ & 20.6 \\
DSC second run & 101.2 & 80.55 & 7.3 \\
o-Ps lifetime third run: heating & $91.5 \pm 2.8$ & $84.2 \pm 2.3$ & 20.7 \\
DSC third run & 101.2 & 80.49 & 3.3 \\
o-Ps lifetime all runs except & $91.2 \pm 2.4$ & $87.9 \pm 3.5$ & \\
first run data below $T_{\mathrm{g}}$ & & & 20.7 \\
DSC all runs & 101.2 & 80.53 & \\
\hline
\end{tabular}

Note: $\Delta T_{\mathrm{g}}$ is the difference of $T_{\mathrm{g}}$ between with and without $\mathrm{CO}_{2}$ polystyrene.

and DSC data vs. temperature for three separate runs and observed the same $T_{\mathrm{g}}$ (within the statistical uncertainties) as listed in Table I. The $T_{\mathrm{g}}$ results are in general in agreement with the existing PAL data [16-32]. The lower observed $T_{\mathrm{g}}$ from PAL than DSC has been explained due to the difference in the experimental time that one data point by PAL (typically $3 \mathrm{~h}$ or $10^{4} \mathrm{~s}$ ) was much longer than DSC (typically $10 \mathrm{~s}$ ). The observed $10^{\circ} \mathrm{C}$ lower $T_{\mathrm{g}}$ from PAL is consistent with that observed from specific volume data for 3 orders of magnitude of experimental time [34].

The free-volume thermal expansion coefficients, $\alpha_{\mathrm{IV}}=\left(\Delta V_{\mathrm{f}} / \Delta T\right) / V_{\mathrm{f}}$, where $V_{\mathrm{f}}$ is the free volume calculated from the free-volume radius $(R)$ based on the spherical model $\left(V_{\mathrm{f}}=4 \pi R^{3} / 3\right)$, for data above and below $T_{\mathrm{g}}$ are listed in Table II. Compared with the bulk volume expansion coefficient measured by the specific volume experiments [35], we found that $\alpha$ for free volumes is about one order of magnitude larger than that for bulk volumes. This is understandable because 
TABLE II

Free-volume and bulk volume thermal expansion coefficients $\left(\alpha_{\mathrm{g}}\right.$, $\alpha_{\mathrm{r}}$ of PS in the glass and the rubbery states.

\begin{tabular}{c|c|c|c|c}
\hline \hline & $\begin{array}{c}\text { Free-volume } \\
\alpha_{\mathrm{g}}\left[\mathrm{K}^{-1}\right]\end{array}$ & $\begin{array}{c}\text { Free-volume } \\
\alpha_{\mathrm{r}}\left[\mathrm{K}^{-1}\right]\end{array}$ & $\begin{array}{c}\text { Bulk-volume } \\
\alpha_{\mathrm{g}}\left[\mathrm{K}^{-1}\right][35]\end{array}$ & $\begin{array}{c}\text { Bulk-volume } \\
\alpha_{\mathrm{r}}\left[\mathrm{K}^{-1}\right][35]\end{array}$ \\
\hline In air $(14.7 \mathrm{psi})$ & $1.43 \pm 0.11 \times 10^{-3}$ & $6.38 \pm 0.10 \times 10^{-3}$ & $2.1 \times 10^{-4}$ & $5.5 \times 10^{-4}$ \\
$400 \mathrm{psi} \mathrm{CO}_{2}$ & $1.90 \pm 0.09 \times 10^{-3}$ & $3.80 \pm 0.07 \times 10^{-3}$ & &
\end{tabular}

PAL measures uniquely for free-volume quantities with about $2-10 \%$ of free-volume fractions in common polymers. It is also interesting to observe that the ratio of $\alpha$ above and below $T_{\mathrm{g}}$ for free volume $\left(\alpha_{\mathrm{r}} / \alpha_{\mathrm{g}}=4.6\right)$ is also larger than that from the bulk $(=2.6)$. These observations of $o$-Ps data vs. $T$ are also in general consistent with the existing PAL data in PS [16-32].

The second observation of $o$-Ps intensity $I_{3}$ difference for the first run from the second and third runs is interesting. During the first run, $I_{3}$ is nearly constant below $T_{\mathrm{g}}$ and a slight fluctuation near $T_{\mathrm{g}}$, and the returns to almost the same $I_{3}$ above $T_{\mathrm{g}}$ again. However, in the second (cooling) and third (heating again), $I_{3}$ increases as a function of temperature (Fig. 1 right). In the un-annealed PS (the first run), PS may contain more free volume and small molecules that show a larger $I_{3}$ than the annealed PS (second and third runs). The thermal cycle has removed those extra $I_{3}$ (about 1-7\%) from the un-annealed Ps sample and the $I_{3}$ increases monotonically as a function of temperature for annealed PS as seen in the second and the third runs (Fig. 1 right).

\section{2. $\mathrm{CO}_{2}$ exposed polystyrene}

Figure 2, the result of $o$-Ps lifetime and intensity as a function of temperature for $400 \mathrm{CO}_{2}$ exposed PS, is very interesting. We have two new observations: (1) During the first run, there is an increase in $o$-Ps lifetime at very low $T$, a decrease at intermediate $T$ and then an increase again at high $T$, while $I_{3}$ increases as a function of temperature monotonically, and (2) during the second (cooling), third (heating) runs, the variations of $o-\mathrm{Ps}$ and $I_{3}$ are similar to common polymers, i.e. increase with $T$. The first observation of a negative free-volume thermal expansion coefficient at low temperature is similar to that reported in two systems, $\mathrm{CO}_{2}$ exposed polycarbonate [14] and $\mathrm{CO}_{2}$ exposed polysulfone [15] by us. There are a few possible processes for the free-volume variations with respect to the temperature in $\mathrm{CO}_{2} / \mathrm{PS}$ : (1) the expansion of the existing holes, (2) creating new holes, (3) re-arrangement of free volumes, (4) diffusion of $\mathrm{CO}_{2}$ from the matrix and filling into the free volume, (5) collapsing the metastable free volumes, and (6) other effects, such as $\beta$-transition, etc. The first two processes and also the third process if small holes combine to become large holes may be responsible for the increase in $\tau_{3}$, i.e. at the very low and high $T$ regions. At the intermediate temperatures, starting from a temperature $T^{\prime}$ the processes of the diffusion of dissolved $\mathrm{CO}_{2}$ from the polymer matrix to fill into the free volumes and also the collapsing of meta-stable free volumes due to $\mathrm{CO}_{2}$ sorption could result in 

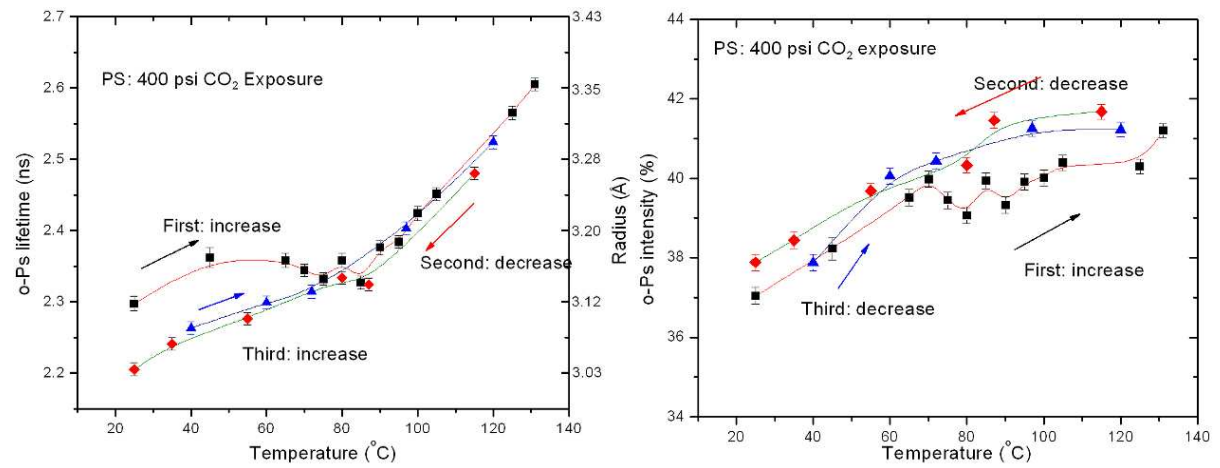

Fig. 2. Ortho-Ps lifetimes and intensities vs. temperature in $400 \mathrm{psi} \mathrm{CO}_{2}$ exposed PS. Lines were smoothed lines drawing through the data points for eye-guide purpose. Three runs from low to high, high to low, and cycle again are as indicated.

a negative thermal expansion coefficient. The $\mathrm{CO}_{2}$ molecule has a rather small kinetic radius $(1.65 \AA)$ and it could be first dissolved in polymer matrix and at certain temperatures, it then diffuses into free volumes which has a mean radius of 3.1-3.2 A. At the same time, some metastable free volumes created due to $\mathrm{CO}_{2}$ sorption may be annealed away. At certain further increased temperature to the apparent $T_{\mathrm{g}}$, the hole expansion, creation, and combination processes become dominating, then the $o$-Ps lifetime variation with respect with temperature follows the normal trend, i.e. increases with $T$. The $\mathrm{CO}_{2}$ diffusion from the matrix to fill holes and the collapsing of metastable free-volume processes are irreversible after the first run as we observed that the normal temperature variations of $o$-Ps lifetime and intensities increase during the second and third runs. The normal temperature dependence is also seen in the $o$-Ps data above $T_{\mathrm{g}}$ during the first run. The $\mathrm{CO}_{2}$ filling and collapsing of metastable free volumes below apparent $T_{\mathrm{g}}$ is also indicated by the $I_{3}$ fluctuation during the first run (Fig. 2 right).

Next, we proceed to analyze the $o$-Ps lifetime vs. $T$ for three separate runs. Figure 3 shows the $o$-Ps lifetime variation for $400 \mathrm{psi} \mathrm{CO}_{2}$ exposed PS during each of three runs. For the first run data (top), we fitted the data into three regions: at the very low $T$ where $\tau_{3}$ increases, at the intermediate $T$ where $\tau_{3}$ decreases with $T$, and then where it increases with $T$ again. Each linear fitted lines are shown and we obtain two intercept $T$ as $T^{\prime}$ and $T_{\mathrm{g}}$, respectively. The region between these two temperatures is where the metastable free volume collapses and $\mathrm{CO}_{2}$ hole filling occurs. The lower $T^{\prime}$ may be indicating the transition temperature for $\mathrm{CO}_{2}$ diffusion from the bulk matrix to the free volume and also for the collapsing the meta-stable free volumes due to the $\mathrm{CO}_{2}$ sorption. The range of this region is between $53^{\circ} \mathrm{C}\left(T^{\prime}\right)$ and $82^{\circ} \mathrm{C}\left(T_{\mathrm{g}}\right)$ for $400 \mathrm{psi} \mathrm{CO}_{2}$ exposed PS. It is also interesting that the $T^{\prime}$ is found to close to the known $\beta$-transition $\left(T_{\beta}=52^{\circ} \mathrm{C}\right)$, which relates to the conformational relaxation in PS $[22,35]$. It is speculated that the $\mathrm{CO}_{2}$ sorption may be related to the conformational structures in PS since the variation 

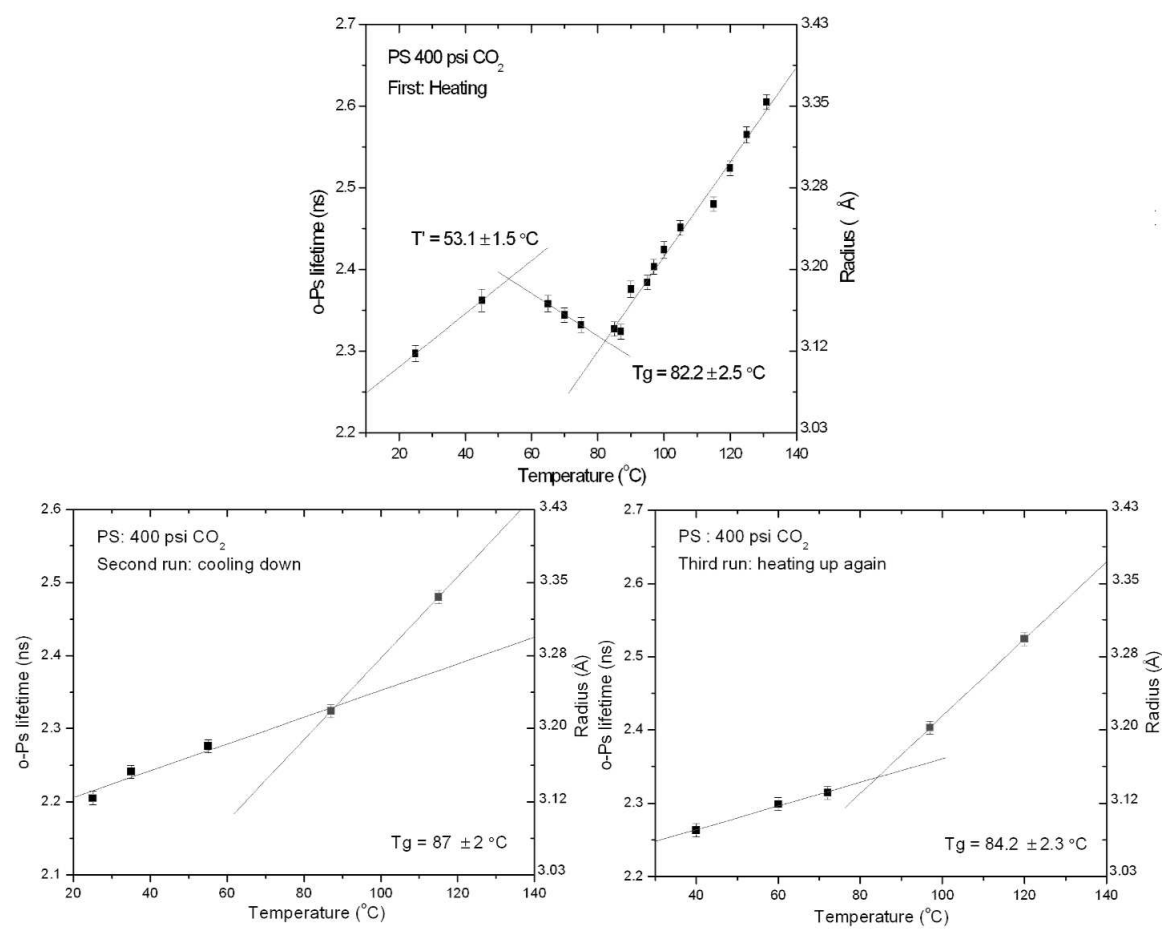

Fig. 3. Ortho-Ps lifetimes vs temperature in 400 psi $\mathrm{CO}_{2}$ exposed PS in three runs: the first run (heating from r.t. up), the second run (cooling down from $150^{\circ} \mathrm{C}$ ), and third run (heating up again from r.t.). Lines were linear fitting and the intercepts are defined as $T_{\mathrm{g}}$ for three respective runs. The lowest intercept temperature is a metastable $T_{\mathrm{g}}$ as labeled as $T^{\prime} /$, which is much lower than others.

near $\beta$ transition is not seen in the un-exposed PS (Fig. 1). On the other hand, during the second and the third runs, the $o$-Ps lifetime data could be fitted into two lines as shown in the lower plots of Fig. 3. We obtained the intercept temperatures as $87.0 \pm 2.0^{\circ} \mathrm{C}$, and $84.2 \pm 2.3^{\circ} \mathrm{C}$, which are much higher than the $T^{\prime}\left(53.1 \pm 1.5^{\circ} \mathrm{C}\right)$ but is about the same as the apparent $T_{\mathrm{g}}\left(82.2 \pm 2.5^{\circ} \mathrm{C}\right)$ during the first run. Table I lists all $T_{\mathrm{g}}$ 's from three runs. Since the $o$-Ps lifetime data after the temperature above $83^{\circ} \mathrm{C}$ all follow two linear trends, we also combined all $o$-Ps lifetimes data for the first run above $83^{\circ} \mathrm{C}$ and all second and third run data and fitted data into two linear lines as shown in Fig. 4. The intercept temperature turns out to be about the same as individual three runs within the statistical errors $\left(T_{\mathrm{g}}=87.9 \pm 3.5^{\circ} \mathrm{C}\right)$ of annealed at 400 psi exposed PS. The mean $T_{\mathrm{g}}$ for annealed $\mathrm{CO}_{2} / \mathrm{PS}$ (the average of first run, $82.2^{\circ} \mathrm{C}$; second run, $87.0^{\circ} \mathrm{C}$, third run, $84.2^{\circ} \mathrm{C}$; and all runs except first run data below $T_{\mathrm{g}}, 87.9^{\circ} \mathrm{C}$ ) from all these analysis is $85.4 \pm 2.6^{\circ} \mathrm{C}$, which shows a $T_{\mathrm{g}}$ suppression of $5.8^{\circ} \mathrm{C}$ compared with the un-exposed PS. 


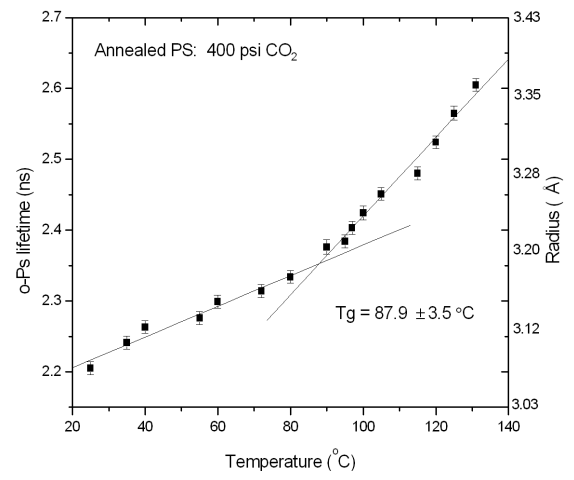

Fig. 4. Ortho-Ps lifetimes vs. temperature in 400 psi (left) $\mathrm{CO}_{2}$ exposed PS for all three runs except the data below $T_{\mathrm{g}}$ during the first run. Lines were linear fitting and the intercepts are defined as the $T_{\mathrm{g}}$ for annealed $\mathrm{CO}_{2} / \mathrm{PS}$.

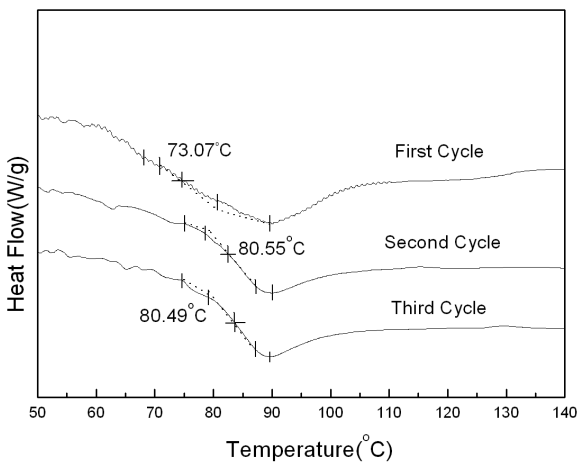

Fig. 5. DSC heat flow vs temperature (left) for three heating cycles of PS at rate $10^{\circ} \mathrm{C} / \mathrm{min}$ for $400 \mathrm{psi}$ three heating cycles (left) and for the second cycles at different $\mathrm{CO}_{2}$ exposure in PS.

We also performd the DSC data in the similar thermal cycles as the PAL and found that the heat flow onset temperatures are $73.1,80.5$, and $80.5^{\circ} \mathrm{C}$, respectively, as shown in Fig. 5 . Table I lists all the $T_{\mathrm{g}}$ results by PAL and DSC. We found that the first $T^{\prime}\left(53.1^{\circ} \mathrm{C}\right)$ from PAL is much lower than DSC data $\left(73.1^{\circ} \mathrm{C}\right)$ or from the dilatometry data $\left(70^{\circ} \mathrm{C}\right)[3,4,36]$. However, those known $T_{\mathrm{g}}\left(70-73^{\circ} \mathrm{C}\right.$ ) are closer to the mid-point temperature $\left(67.6 \pm 2.0^{\circ} \mathrm{C}\right)$ between $T^{\prime}\left(53.1^{\circ} \mathrm{C}\right)$ and $T_{\mathrm{g}}\left(82.2^{\circ} \mathrm{C}\right)$, from the first run where the metastable free volume exists but they are much lower than the $T_{\mathrm{g}}$ from the second $\left(87.0^{\circ} \mathrm{C}\right)$ and third run $\left(84.2^{\circ} \mathrm{C}\right)$ data by PAL. Therefore, we observed that $T_{\mathrm{g}}$ from PAL are higher than DSC data by $1.7-7.4^{\circ} \mathrm{C}$ or an average by $4.9^{\circ} \mathrm{C}$ higher $\left(85.4-80.5^{\circ} \mathrm{C}\right)$. The mid-point temperature in the region where metastable free volume exits may be referred to as a metastable $T_{\mathrm{g}}$ for $400 \mathrm{psi} \mathrm{CO}_{2}$ sorption PS. This is very different from that in the un-exposed PS that the $T_{\mathrm{g}}$ from PAL is $10^{\circ} \mathrm{C}$ lower than DSC result and no 
metastable $T_{\mathrm{g}}$ exists. One plausible explanation to this opposite difference is that the difference in the sample thermal history between PAL and DSC is that PAL experiments took about two weeks and DSC took only one hour. During this long period of PAL experiments under 400 psi $\mathrm{CO}_{2}$ exposure, the nano- and microstructure of $\mathrm{CO}_{2} / \mathrm{PS}$ may have been changed. The other plausible reason is that $\mathrm{CO}_{2}$ sorption in PS may be related to the $\beta$ transition as observed by PAL but not seen in un-exposed PS or by DSC method. Further systematic PAL and DSC parallel studies as a function of age will be helpful to understand the relationship between free volume and thermal relaxations in $\mathrm{CO}_{2}$ exposed polymeric systems.

We also calculated the free-volume thermal expansion coefficients $(\alpha)$ for $\mathrm{CO}_{2}$ exposed PS above and below $T_{\mathrm{g}}$ in a procedure similar to that for the unexposed PS above. The results are listed in Table II. It is interesting to observe an increase in $\alpha_{\mathrm{g}}$ and a decrease in $\alpha_{\mathrm{r}}$ due to $\mathrm{CO}_{2}$ sorption and also the difference of $\alpha$ above and below $T_{\mathrm{g}}$ becomes smaller due to $\mathrm{CO}_{2}$ sorption in PS although its values are still much larger than the bulk's [35]. This may indicate that at high pressure where $\mathrm{CO}_{2}$ is approaching to its supercritical state, the behavior of Ps probe in high sorption $\mathrm{CO}_{2}$-polymer systems may not be similar to those un-exposed systems, such as trapping-detrapping of $o$-Ps in free volumes and Ps bubble formation, etc. Future studies of $o$-Ps in supercritical systems will be very useful in this line of $\mathrm{CO}_{2}$-polymer composite systems.

Finally, we reported the free-volume distribution in the $\mathrm{CO}_{2}$ exposure and temperature dependence in Fig. 6 as obtained from MELT analysis. It is interesting to observe that the free volume distribution shows a broad distribution due to $\mathrm{CO}_{2}$ sorption. The sorption of $\mathrm{CO}_{2}$ swells the existing holes and also creates smaller and larger holes as seen in the plot of Fig. 6 (left). For the temperature dependence (Fig. 6 right), the free volume expands and at the same time it distributes wider as the temperature increases.
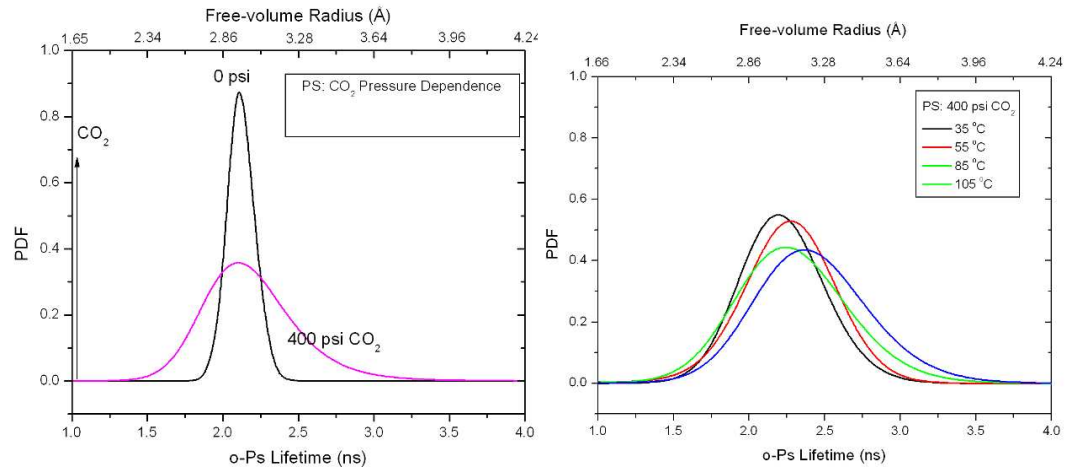

Fig. 6. Ortho-Ps lifetime (free-volume radius) distributions in polystyrene for with and without $\mathrm{CO}_{2}$ exposure (left) and for $\mathrm{CO}_{2}$ exposed at different temperatures (right). 
In conclusion, PAL has been used to determine free-volume size and distribution in a polystyrene with and without $\mathrm{CO}_{2}$ sorption. The observed $T_{\mathrm{g}}$ from ortho-positronium lifetimes were found to be $86^{\circ} \mathrm{C}$ and $91^{\circ} \mathrm{C}$, which are $5^{\circ} \mathrm{C}$ higher, and $10^{\circ} \mathrm{C}$ lower than from the DSC data for with and without $\mathrm{CO}_{2}$ exposed PS, respectively. In the annealed $\mathrm{CO}_{2}$ exposed polystyrene, $T_{\mathrm{g}}$ was found to suppress by only $4.9^{\circ} \mathrm{C}$, which is much less than from DSC (by $20.9^{\circ} \mathrm{C}$ ). A metastable state showing a negative thermal expansion coefficient was observed between $53^{\circ} \mathrm{C}$ and $82^{\circ} \mathrm{C}$ during the first heating up experiment. Positron annihilation spectroscopy may be useful for the understanding of gas sorption and its effects on nano- and microstructures as well as the transition phenomena.

\section{Acknowledgments}

This research is supported by the NSF-sponsored Nanoscale Science and Engineering Center for Affordable Nanoengineering of Polymeric Biomedical Devices (NSEC-CANPBD) at the Ohio State University and sub-contract to the University of Missouri-Kansas City. One of us (YCJ) would like to thank the hospitality of Prof. J.-Y. Lai for his on-leave at the Center of Membrane Technology, ChungYuan Christian University, Taiwan.

\section{References}

[1] D.L. Tomasko, H. Li, D. Liu, X. Han, M. Wingert, L. James Lee, K.W. Koelling, Ind. Eng. Chem. Res. 42, 6431 (2003).

[2] W. Strauss, N.A. D'Souza, J. Cellular Plastics 40, 229 (2004).

[3] W.J. Koros, D.R. Paul, J. Polym. Sci., Part B, Polym. Phys. 16, 2171 (1976).

[4] J.S. Chiou, J.W. Barlow, D.R. Paul, J. Appl. Polym. Sci. 30, 2633 (1985).

[5] M.H. Cohen, D.J. Turnbull, J. Chem. Phys. 31, 1164 (1959).

[6] J.S. Vrentas, J.L. Duda, J. Polym. Sci., Part B, Polym. Phys. 15, 403 (1977).

[7] J.Y. Park, D.R. Paul, J. Membr. Sci. 125, 23 (1997).

[8] For example, see Y.C. Jean, Microchem. J. 42, 72 (1990).

[9] For example, see P.E. Mallon, in: Principles and Applications of Positron and Positronium Chemistry, Ed. Y.C. Jean, P.E. Mallon, D.M. Schrader, World Sci., Singapore 2003, p. 253.

[10] S.J. Tao, J. Chem. Phys. 56, 5499 (1972).

[11] M. Eldrup, D. Lightbody, J.N. Sherwood, Chem. Phys. 63, 51 (1981).

[12] H. Nakanishi, S.J. Wang, Y.C. Jean, in: Positron Annihilation Studies of Fluids, Ed. S.C. Sharma, World Sci., Singapore 1988, p. 292.

[13] Y. Ito, M.F.M. Mohamed, K. Tanaka, K. Okamoto, K.J. Lee, J. Radioanal. Nucl. Chem. 210, 211 (1996).

[14] X. Hong, Y.C. Jean, S. Yang, S.S. Jordon, W.J. Koros, Macromolecules 29, 7859 (1996).

[15] J.-P. Yuan, H. Cao, E.W. Hellmuth, Y.C. Jean, J. Polym. Sci., Part B, Polym. Phys. 36, 3049 (1998). 
[16] J. Liu, Q. Deng, Y.C. Jean, Macromolecules 26, 7149 (1993).

[17] A. Uedono, T. Kawano, S. Tanigawa, M. Ban, M. Kyoto, T. Uozomi, J. Polym. Sci. Part B, Polym. Phys. 34, 2145 (1996).

[18] H.L. Li, Y. Ujihira, A. Nanasawa, J. Radioanal. Nucl. Chem. 210, 533 (1996).

[19] C.L. Wang, S.J. Wang, Polymer 38, 173 (1997).

[20] W.J. Davis, R.A. Pethrick, Polym. Int. 45, 395 (1985).

[21] K. Ito, Y. Ujihira, Polym. J. 30, 566 (1998).

[22] Z.L. Peng, B.G. Olson, J.D. McGervey, A.M. Jamieson, Polymer 40, 3033 (1999).

[23] J. Bohlen, R. Kirchheim, Macromolecules 34, 4210 (2001).

[24] M. Song, D.J. Hourston, G.G. Silva, J.G. Machado, J. Polym. Sci. Part B, Polym. Phys. 39, 1659 (2001).

[25] V.P. Shantarovich, T. Suzuki, C. He, V.A. Davankov, A.V. Pastukhov, M.P. Tsyurupa, K. Kondo, Y. Ito, Macromolecules 35, 9723 (2002).

[26] C. He, T. Suzuki, E. Hamada, H. Kobayashi, K. Kondo, V.P. Shantarovich, Y. Ito, Mater. Res. Innovations 7, 37 (2003).

[27] G. Dlubek, J. Pionteck, D. Kilburn, Macromol. Chem. Phys. 205, 500 (2004).

[28] D. Cangialosi, M. Wubbenhorst, H. Schut, A. van Veen, S.J. Picken, J. Chem. Phys. 122, 64702 (2005).

[29] G. Consolati, F. Quasso, R. Simha, B.G. Olson, J. Polym. Sci., Part B, Polym. Phys. 43, 2225 (2005).

[30] J. Zhang, H. Chen,Y. Li, R. Suzuki, T. Ohdaira, Y.C. Jean, J. Radiat. Phys. Chem. 76, 172 (2007).

[31] N. Djiourelov, C. Dauwe, C.A. Palacio, N. Laforest, C. Bas, Phys. Status Solidi C 1-4, 1002 (2007).

[32] Y. Honda, T. Shimada, M. Tashiro, N. Kimura, Y. Yashida, G. Isoyama, S. Tagawa, J. Radiat. Phys. Chem. 76, 169 (2007).

[33] Y. Yang D. Liu, Y. Xie, L. James Lee, D.L. Tomasko, Adv. Mater. 19, 251 (2007).

[34] R. Greiner, F.R. Schwartl, Rhod. Acta 23, 378 (1984).

[35] Physical Properties of Polymers Handbook, Ed. J.E. Mark, Am. Inst. Phys., Woodbury, NY 1996, p. 87.

[36] M.D. Sefcik, J. Polym. Sci., Part B, Polym. Phys. 24, 958 (1986). 